\title{
CLIMATE CHANGE AND COASTAL DEFENCES IN TOKYO BAY
}

\author{
Sayaka Hoshino', Miguel Esteban², Takahito Mikami³ ${ }^{3}$ Tomoyuki Takabatake ${ }^{4}$, Tomoya \\ Shibayama $^{5}$
}

\begin{abstract}
Sea level rise and an increase in typhoon intensity are two of the expected consequences from future climate change. In the present work a methodology to change the intensity of tropical cyclones in Japan was developed, which can be used to assess the inundation risk to different areas of the country. An example of how this would affect one of the worst typhoons to hit the Tokyo Bay area in the 20th century was thus developed, highlighting the considerable dangers associated with this event, and how current sea defences could be under danger of failing by the end of the 21 st century.
\end{abstract}

Keywords: storm surge; sustainability of coastal defences; sea level rise, typhoons

\section{INTRODUCTION}

Every year, Japan is attacked by a number of tropical cyclones, some of which can be very strong and cause widespread damage. Apart from wind damage, these events also generate powerful waves and storm surges, which can inundate coastal areas and lead to the destruction of property and the loss of lives. Global warming as a consequence of increasing concentrations of greenhouse gases in the atmosphere could lead to an increase in the intensity in tropical cyclones in the future, which would compound the problems already presented by sea level rise (also expected to accelerate in the course of the 21 st century). Tropical cyclones need high surface sea temperatures to form (typically at temperatures of over $26^{\circ} \mathrm{C}$ ), and use the heat from the evaporation of sea water to maintain or increase their strength. Once they move over land or into colder areas their power starts to wane, and hence it appears logical that future increases in global temperatures will increase the intensity of these events.

A number of authors (such as Knutson and Tuleya, 2004, Elsner et al., 2008, Landsea et al., 2006, Webster and Holland, 2005) have carried out research using supercomputers showing how it appears likely that tropical cyclones will increase in intensity in the future. However, the IPCC reports that although there is general agreement that tropical cyclones are likely to increase in intensity there is no consensus yet on the future frequency of these events. Also, it is believed that there is a certain cyclical variability in the natural patterns of tropical cyclones, which could be due to short-scale decadal cycles such as the El Niño-Southern Oscillation, or ENSO (Mousavi et al., 2011). This short term variations make assessments of future increases in intensity difficult, and Pielke (2007) reports how nine of the leading scholars on tropical cyclones and climate change give estimates ranging from a 0 to 36 per cent increase in tropical cyclone intensity by the year 2100. More recently Knutson et al (2010) summarised all the most important work on tropical cyclone simulations, including recent research that was done using higher resolution models than those used in the work that led to the IPCC 4AR. This review appears to suggest that the intensity of tropical cyclones in the future could increase by between 2 and $11 \%$ by 2100 , depending on the simulation used and the part of the world concerned. It is important to emphasize how Knutson et al. (2010) find that the higher resolution models predict higher increases in tropical cyclone intensity than those with lower resolution, and thus it is possible that the models presently employed might be underestimating potential future problems.

However, an intensification of tropical cyclones is not the only potential factor that could increase the inundation of low-lying coastal areas in Japan. During the 20th century the global average sea level rose by an average of around $1.7 \mathrm{~mm}$ per year, with satellite observations showing that since 1993 sea level has been rising at a rate of around $3 \mathrm{~mm}$ per year, according to the 4th Assessment Report of the Intergovernmental Panel on Climate Change, or 4th IPCC. Future projections of sea level rise show that sea level could be between 0.18 and $0.59 \mathrm{~m}$ higher than at present by the end of the 21 st century. As at present $\mathrm{CO}_{2}$ emissions continue to increase global temperatures are also likely to continue to increase, and thus it appears that a significant amount level of sea rise is inevitable unless drastic action is taken to reduce emissions. Furthermore, the IPCC 4AR notes that "atmospheric $\mathrm{CO}_{2}$ will continue to increase

\footnotetext{
${ }^{1}$ Waseda University, 3-4-1 Ookubo, Shinjuku-ku, Tokyo 169-8555, Japan, sayahoshi0905@goo.jp

2 Waseda University, 3-4-1 Ookubo, Shinjuku-ku, Tokyo 169-8555, Japan, esteban.fagan@gmail.com

${ }^{3}$ Waseda University, 3-4-1 Ookubo, Shinjuku-ku, Tokyo 169-8555, Japan, t.mikami@asagi.waseda.jp

4 Taisei Corporation, Japan

${ }^{5}$ Waseda University, 3-4-1 Ookubo, Shinjuku-ku, Tokyo 169-8555, Japan, shibayama@waseda.jp
} 
in the long term even if it's emission is substantially reduced from present levels" as these particles are not easily eliminated once they have been released into the atmosphere. Future patterns of sea level rise are uncertain due to a lack of understanding of the exact way in which the global climate works, and especially how the big ice sheets of Greenland and Antarctica will respond to increases in temperature (Allison et al., 2009). In fact, many researchers now believe that sea level by 2100 is likely to rise much more the range of $0.18-0.59 \mathrm{~m}$ given in the IPCC 4AR. The research highlighted in this report did not include representations of dynamic ice sheets, and hence only included simple mass balance estimates of the contributions from Greenland and the Arctic ice sheets. In fact the IPCC 4AR report assumed that ice was accumulating over the Antarctic ice sheet, though currently it appears that it is losing mass as a consequence of dynamic processes (Allison et al., 2009). More extreme scenarios, such as those by Vermeer and Rahmstorf (2009), thus argue that sea level rise could be in the range of 0.81 to $1.90 \mathrm{~m}$ by 2100.

Though the cities around Tokyo Bay are generally well protected by coastal structures against storm surge, the combination of sea level rise and an increase in typhoon intensity could eventually require the strengthening of these defences to mitigate against these effects of climate change. In the present work the authors present a methodology of how to modify the strength of future typhoons using the results of Yasuda et al. (2010) and based on historical events use this methodology to determine the significance of climate change to coastal structures in one case study area (Tokyo Bay).

\section{METHODOLOGY}

The present work uses as a case study the typhoon of October 1917 (6th year of the Taisho period Typhoon), which was the worst typhoon to affect Tokyo Bay in the last 100 years. In order to simulate the expected future increase in typhoon intensity the authors used the probability distribution functions provided by Yasuda et al. (2010), outlining the present and future expected intensity of typhoons in the Tokyo Bay area. To determine the storm surge a 2-level model was used. The governing equations in the model are the mass conservation equation and the momentum conservation equation. One of the main problems of this model lies in determining the radius of maximum wind speeds. To overcome this problem the method of Yasuda et al. (2010) was used, where the radius is not given a deterministic value but rather follows a probabilistic curve. Finally, the effect of sea level rise is added to that of the storm surge to calculate the final level of sea defences that would be required for a given scenario.

\section{Study Area}

The target areas of study are the Tokyo and Sagami Bays. The simulation uses a nesting approach, and hence the area is divided into 2 levels of calculation, one with a larger grid size than the other. For the large area, the dimension of each grid is 30 seconds (around $3 \mathrm{~km}$ ), and for small grid size the dimension is 10 seconds (around $1 \mathrm{~km}$ ), with the small area covering only Tokyo Bay (see Figure 1). Figure 2 and Table 1 show the location of the points which were studied along the Bay, for which storm surge levels were recorded for each of the tropical cyclone simulations that were carried out. 


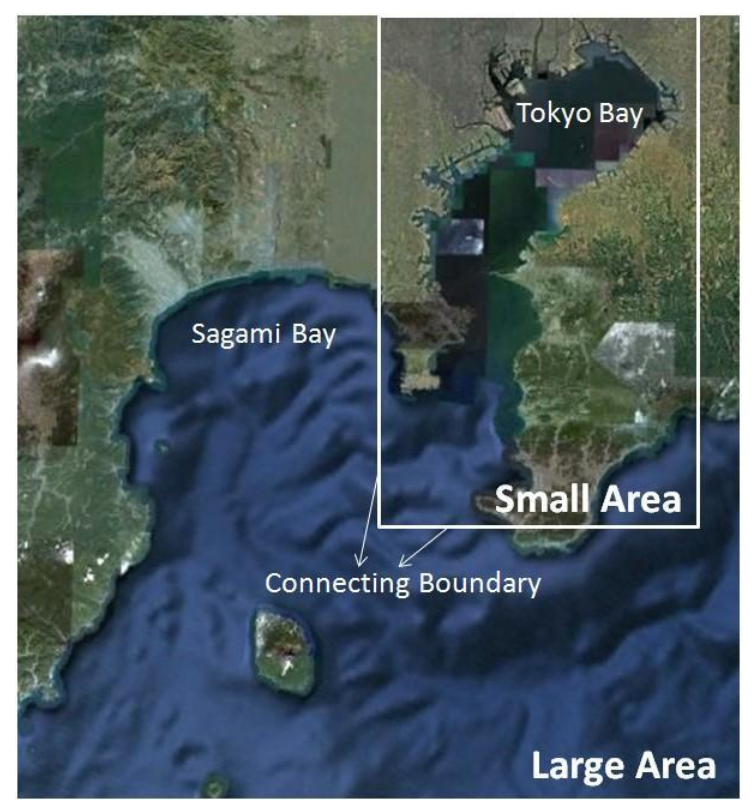

Figure 1. Study area showing Tokyo Bay and adjacent sea areas

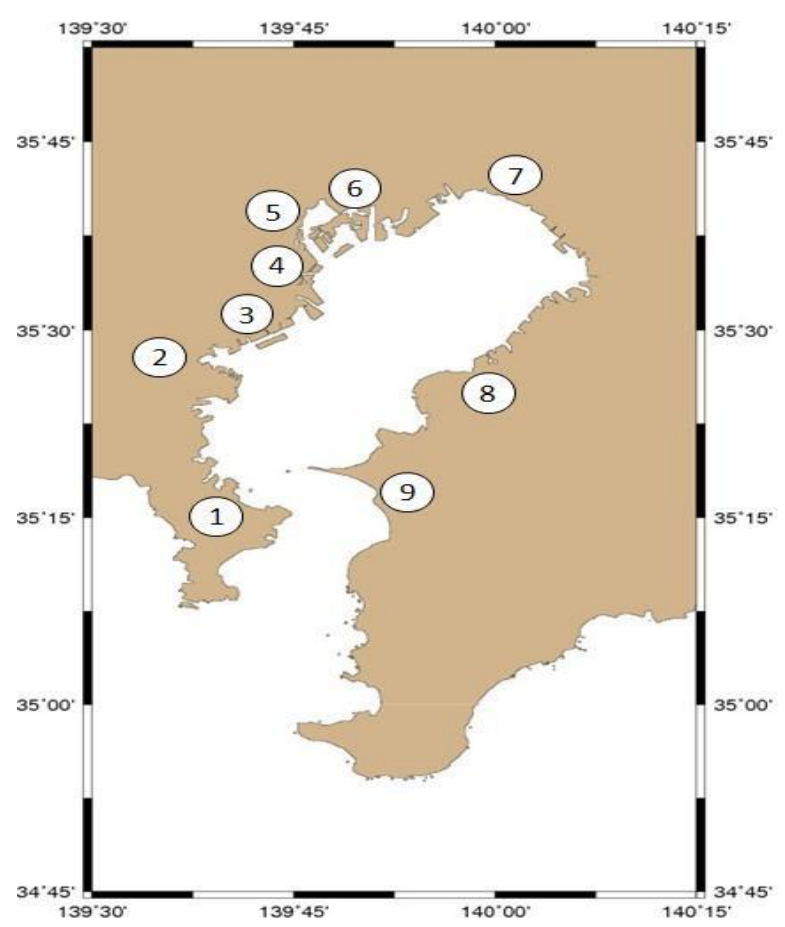

Figure 2. Summary of points of interest along Tokyo Bay 


\begin{tabular}{|c|c|c|}
\hline \multicolumn{2}{|l|}{ Table 1. } \\
Location of simulated locations, with \\
respective prefectures. \\
\hline No & Place-name & Prefecture \\
\hline 1 & Yokosuka & \\
2 & Yokohama & Kanagawa \\
3 & Kawasaki & \\
\hline 4 & Samezu & \\
5 & Shibaura & Tokyo \\
6 & Toyosu & \\
\hline 7 & Funabashi & \\
8 & Sodegaura & Chiba \\
9 & Futtsu & \\
\hline
\end{tabular}

\section{Taisho $6^{\text {th }}$ year (1917) typhoon}

The Taisho (1917) Typhoon was the worst typhoon to affect Tokyo Bay in the last 100 years. It caused widespread damage in the Tokyo Bay area, and from past historical records it flooded an area of over $200 \mathrm{~km}^{2}$, with the number of dead and missing estimated to be over 1300 people (Table. 2). The typhoon did not pass directly above Tokyo Bay but slightly to the west of it, as shown in Figure 3 . The lowest pressure of the typhoon was said to be $952.7 \mathrm{hPa}$ according to Miyazaki (2003), though the way in which pressure was measured in 1917 is slightly different to the way it is done now (the original way to measure the central pressure of a typhoon was to carry out plane observations).

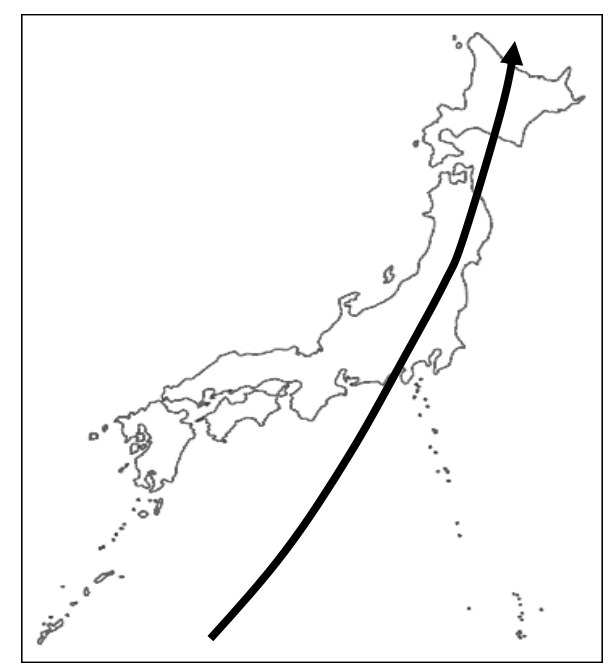

Figure 3. Route of Taisho (1917) Typhoon

\begin{tabular}{|l|l|}
\hline \multicolumn{2}{|l|}{ Table 2. The damage caused by Taisho (1917) typhoon. } \\
\hline Dead or missing & 1,324 \\
\hline Wounded & 2,022 \\
\hline Completely destroyed houses & 36,459 \\
\hline Half destroyed houses & 21,274 \\
\hline Houses washed away & 2,442 \\
\hline Flooded houses & 302,917 \\
\hline Flooded area & $215 \mathrm{~km}^{2}$ (in Tokyo) \\
\hline
\end{tabular}




\section{Storm Surge Simulation Model}

To simulate storm surge height, a 2-level model was used, as illustrated in Figure 4. This 2-level model was introduced into the calculation of storm surge by Tsuchiya et al (1981). The model has been used by many researchers in the past (such as by Toki et al. (1990)), who have verified its validity against a number of historical typhoons. Nevertheless, for the present simulation the authors also checked that the storm surge results of the historical typhoon matched those simulated at different locations along Tokyo Bay. A 2-level model considers the influence of wind, so it is more effective for shallow water such as Tokyo Bay to use 2-level model than 1-level model. The governing equations are the mass conservation equation and the momentum conservation equation. For the case of storm surge it is important to consider also the effect of wind induced waves, shear stress due to wind at water surface, shear stress between upper layer and lower layer, and sea bottom shear stress. Therefore, governing equations for storm surge can be expressed in Eqs. (1)-(5)

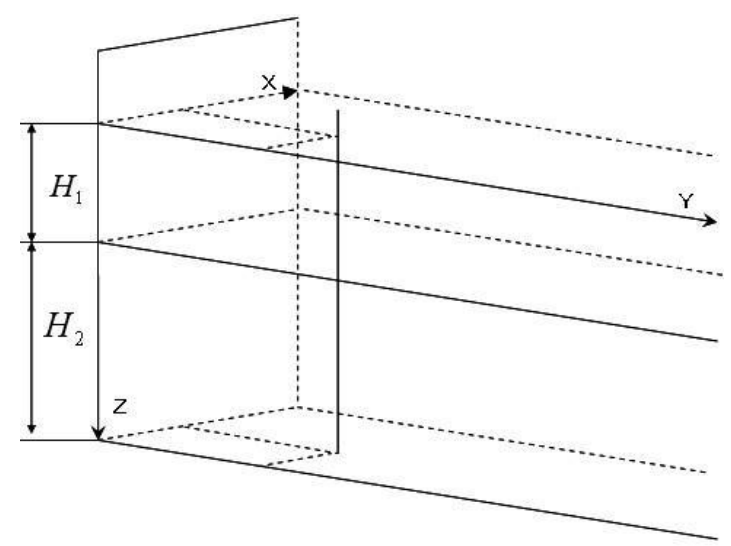

Figure 4. 2-level model diagram

$$
\begin{aligned}
& \frac{\partial \eta}{\partial t}+\frac{\partial}{\partial x}\left(M_{1}+M_{2}\right)+\frac{\partial}{\partial y}\left(N_{1}+N_{2}\right)=0 \\
& \frac{\partial M_{1}}{\partial t}+\frac{\partial}{\partial x}\left(\frac{M_{1}^{2}}{H_{1}}\right)+\frac{\partial}{\partial y}\left(\frac{M_{1} N_{1}}{H_{1}}\right)+g H_{1} \frac{\partial \eta}{\partial x}+f N_{1}+\frac{H_{1}}{\rho_{w}} \frac{\partial P}{\partial x} \\
& -\frac{\tau_{s x}}{\rho_{w}}-A_{h}\left(\frac{\partial^{2} M_{1}}{\partial x^{2}}+\frac{\partial^{2} M_{1}}{\partial y^{2}}\right)+\frac{\tau_{i x}}{\rho_{w}}+(u w)_{i}=0 \\
& \frac{\partial N_{1}}{\partial t}+\frac{\partial}{\partial x}\left(\frac{M_{1} N_{1}}{H_{1}}\right)+\frac{\partial}{\partial y}\left(\frac{N_{1}^{2}}{H_{1}}\right)+g H_{1} \frac{\partial \eta}{\partial y}+f M_{1}+\frac{H_{1}}{\rho_{w}} \frac{\partial P}{\partial y} \\
& -\frac{\tau_{s y}}{\rho_{w}}-A_{h}\left(\frac{\partial^{2} N_{1}}{\partial x^{2}}+\frac{\partial^{2} N_{1}}{\partial y^{2}}\right)+\frac{\tau_{i y}}{\rho_{w}}+(u w)_{i}=0 \\
& \frac{\partial M_{2}}{\partial t}+\frac{\partial}{\partial x}\left(\frac{M_{2}^{2}}{H_{2}}\right)+\frac{\partial}{\partial y}\left(\frac{M_{2} N_{2}}{H_{2}}\right)+g H_{2} \frac{\partial \eta}{\partial x}+f N_{2}+\frac{H_{2}}{\rho_{w}} \frac{\partial P}{\partial x} \\
& -\frac{\tau_{s x}}{\rho_{w}}-A_{h}\left(\frac{\partial^{2} M_{2}}{\partial x^{2}}+\frac{\partial^{2} M_{2}}{\partial y^{2}}\right)+\frac{\tau_{i x}}{\rho_{w}}+(u w)_{i}=0
\end{aligned}
$$




$$
\begin{aligned}
& \frac{\partial N_{2}}{\partial t}+\frac{\partial}{\partial x}\left(\frac{M_{2} N_{2}}{H_{2}}\right)+\frac{\partial}{\partial y}\left(\frac{N_{2}^{2}}{H_{2}}\right)+g H_{2} \frac{\partial \eta}{\partial y}+f M_{2}+\frac{H_{2}}{\rho_{w}} \frac{\partial P}{\partial y} \\
& -\frac{\tau_{s y}}{\rho_{w}}-A_{h}\left(\frac{\partial^{2} N_{2}}{\partial x^{2}}+\frac{\partial^{2} N_{2}}{\partial y^{2}}\right)+\frac{\tau_{i y}}{\rho_{w}}+(u w)_{i}=0
\end{aligned}
$$

Where $\eta$ is water surface profile above still water level, $h$ is the still water level, $H_{l}=\eta+h_{i}, H_{2}=h$ $+h_{i}, g$ is acceleration of gravity, $x, y$ are horizontal coordinates, $t$ is time, $M$ and $N$ are $x, y$ component of momentum flux, $\tau_{s}$ is water surface shear stress due to wind, $\tau_{b}$ is sea bottom shear stress, $\tau_{i}$ is shear stress between upper layer and lower layer, $\rho_{w}$ is sea water density, and $n$ is Manning's friction factor. Subscript 1 is used for the upper layer and 2 for lower layer. The pressure term is governed by Myers's formula (1954):

$$
P=P_{0}-\Delta P \exp \left(-\frac{r_{\max }}{r}\right)
$$

where $P$ is pressure at a point that has distance $r$ from center of typhoon, $P_{0}$ is lowest pressure at the center of typhoon, $\Delta P$ is the different in pressure between the center of typhoon and the normal air pressure, and $r_{\max }$ is the radius of maximum wind speed.

\section{Estimation of Central Pressure}

To understand how future increases in tropical cyclone intensity will affect storm surge it is necessary to estimate what will be the future central pressure of a given event. In order to do so, the authors used the results of the work of Yasuda et al. (2010). These authors used an Atmospheric General Circulation Model (AGCM) with T959L60 resolution (equivalent to about $20 \mathrm{~km} \mathrm{mesh),} \mathrm{which}$ was newly developed for the KAKUSHIN program (Kitoh et al., 2009). Time slice experiments were conducted for three climate periods of 1979-2004 (present climate), 2015-2031 (near future climate) and 2075-2100 (future climate) with different SSTs (Sea Surface Temperatures). SSTs were used as an external forcing of the AGCM as a bottom boundary condition. The observed SST from the UK Met Office Hadley Centre (HadlSST) were used for the present climate conditions, and the ensemble mean SSTs from CMIP3 multi-model projections of SRES A1b were employed for the future climate experiments.

By using this AGCM, Yasuda et al. (2010) established a stochastic typhoon model (STM), which are used in engineering applications. An STM is a kind of Monte Carlo simulation which calculates key typhoon parameters as functions of central pressure, speed, direction along its trajectory, based on statistical characteristics of observer data.

The study by Yasuda et al. (2010) thus reports on the STM from cyclogenesis to cyclolysis without distinction of season based on the observed typhoon track data (the so-called best track data) from the RSMC-TTC (the Regional Specialized Meteological Center, Tokyo-Typhoon Center) to assess the accuracy and bias tendencies of AGCM projections. RSMC-TTC contains 1468 observed typhoons from 1951 to 2005 .

Fig. 5 shows present and future probability distribution of typhoons around Tokyo Bay according to the results of Yasuda et al. (2010). By doing an integral calculation, the authors converted these results into a cumulative distribution function (Fig.6(a)). According to this, for example, a typhoon that had a central pressure of $970(\mathrm{hPa})$ under present climate condition would have a central pressure of $960(\mathrm{hPa})$ in future as shown in Fig.6(b). For the case of the Taisho typhoon, the historical central pressure of 952.7(hPa) would correspond to a $933.9(\mathrm{hPa})$ in under the assumed climate conditions of the year 2100 . 


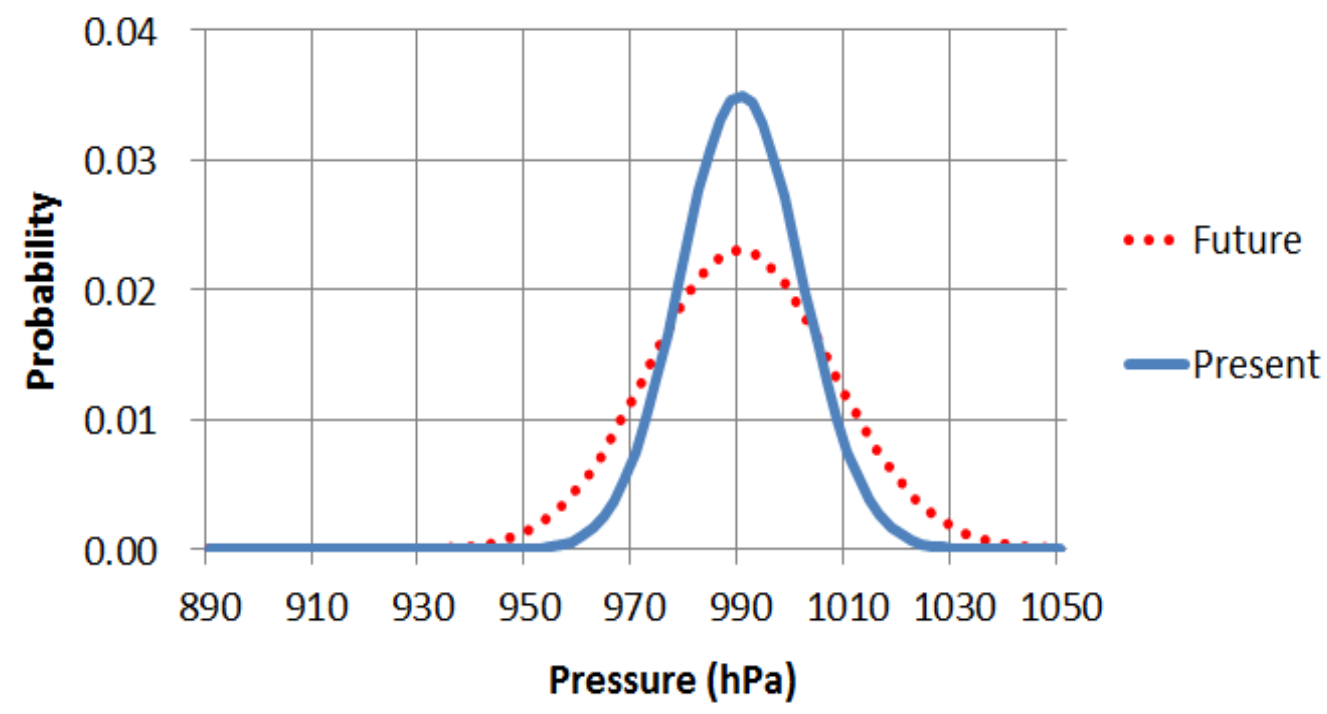

Figure 5. Present and future probability distribution of typhoon intensity at Tokyo Bay

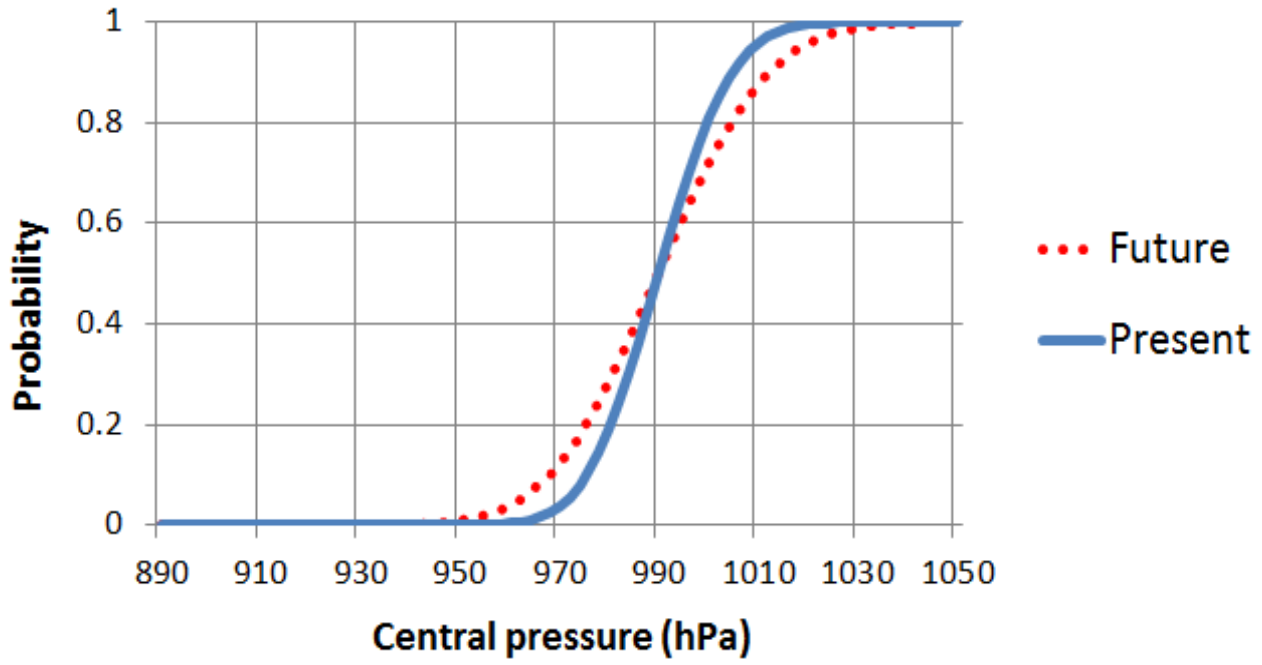

Figure 6. (a) Cumulative distribution function 


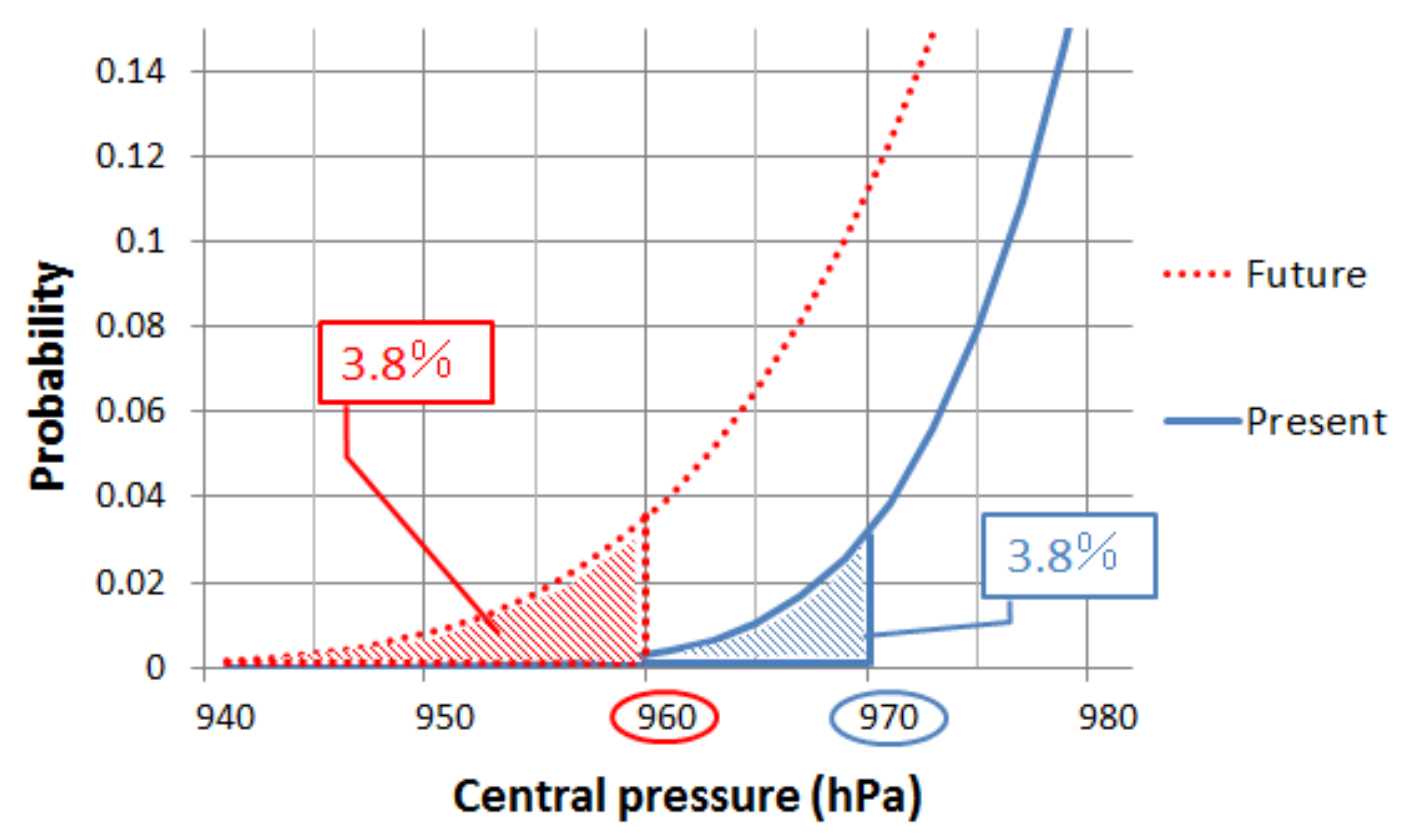

Figure 6. (b) A part of cumulative distribution function

\section{Estimation of Radius of Maximum Wind Speed}

One of the main problems of this model lies in determining the radius of maximum wind speeds $r_{\text {max }}$, which is necessary for the correct resolution of the Myers formula (1954). To overcome this problem the method of Yasuda et al. (2010) was used. In their study, a stochastic typhoon model was established which analysed the distribution and central pressure of typhoons in the northwest Pacific. The relationship between radius of maximum wind speed and central atmospheric pressure was analyzed and parameterized into the probability distribution functions.

\section{Sea level rise}

Future patterns in sea level rise are highly uncertain due to a lack of understanding of the precise working of global climate and its interaction with the physical environment. Much of this is down to uncertainty in the response of the big ice sheets of Greenland and Antarctica (Allison et al., 2009). In fact, it is currently believed that sea level is likely to rise much more by 2100 than the range of 0.18 $0.59 \mathrm{~m}$ given in the IPCC 4AR. In this report, the coupled models used for the 21 st century sea level projections did not include representations of dynamic ice sheets, only including simple mass balance estimates of the contributions from Greenland and the Arctic ice sheets. In fact the IPCC 4AR assumed that ice was accumulating over the Antarctic ice sheet, though this is currently losing mass as a consequence of dynamical processes, as shown in Allison et al., (2009). Recent research such as that by Vermeer and Rahmstorf (2009) show how sea level rise for the period 1990-2100 could be in the 0.75 to $1.9 \mathrm{~m}$ range.

Because of all this uncertainty, the authors decided to use a number of different sea level rise scenarios, as summarized in Table 3. The first scenario does not consider any sea level rise. Although this would appear unrealistic the authors wanted to consider this to observe the effect that an increase in typhoon intensity would have on coastal defences, neglecting sea level rise. The next scenarios represent a sea level rise of $0.28 \mathrm{~m}$ (which would be similar to that of the scenario B1 of the IPCC). Then, the authors also considered the higher range scenario presented in the IPCC 4 AR $(0.59 \mathrm{~cm})$ together with the more extreme scenario outlined in Vermeer and Rahmstorf (2009). 


\begin{tabular}{|c|c|c|c|}
\hline \multicolumn{4}{|c|}{ Summary of Scenarios Considered } \\
\hline $\begin{array}{l}\text { Historical } \\
\text { Central } \\
\text { Pressure }\end{array}$ & $\begin{array}{l}\text { Climate- } \\
\text { change } \\
\text { modified } \\
\text { central } \\
\text { pressure }\end{array}$ & $\begin{array}{l}\text { Radius of maximum } \\
\text { wind speed }\end{array}$ & Sea level rise \\
\hline \multirow{4}{*}{952.7} & \multirow{4}{*}{933.9} & \multirow{4}{*}{$\begin{array}{l}\text { Probability distribution } \\
\text { function according to } \\
\text { Yasuda et al. (2010), } \\
10 \text { computations } \\
\text { for each scenario }\end{array}$} & $0(\mathrm{~cm})$ \\
\hline & & & $28(\mathrm{~cm})$ \\
\hline & & & $59(\mathrm{~cm})$ \\
\hline & & & $190(\mathrm{~cm})$ \\
\hline
\end{tabular}

\section{Typhoon path}

The simulation model used requires the typhoon path to be approximated as a straight line, and thus the historical path of the typhoon (see Fig. 3) was approximated as that shown in Typhoon course Fig.7.

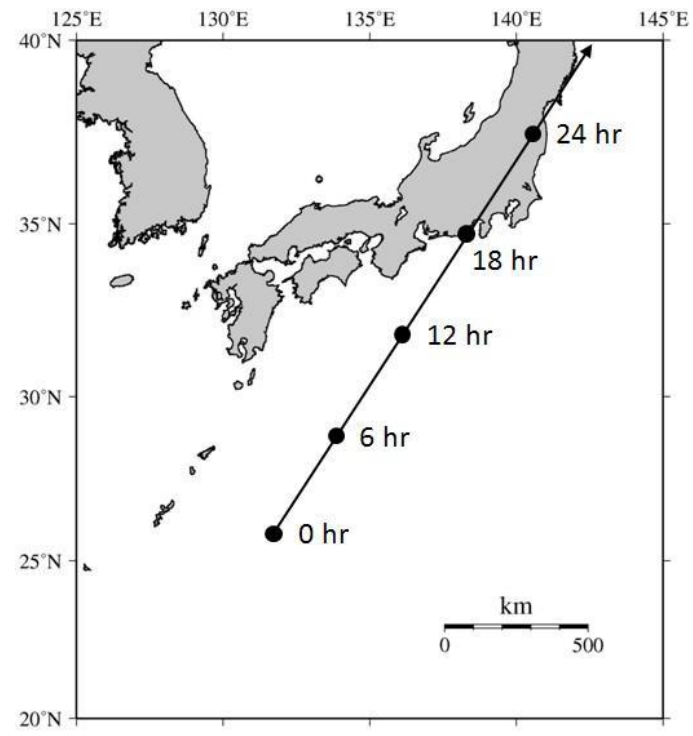

Figure 7. Simulated typhoon course 


\section{RESULTS}

To calculate the storm surge for the modified tropical cyclone it is necessary to consider the central pressure, radius of maximum wind speed and sea level rise, as mentioned earlier. As the methodology of Yasuda et al. (2010) is probabilistic, this also results in a probabilistic answer, where the storm surge for a given central pressure takes a range of possible values. The results shown in Fig. 8 compute the maximum storm surge that could be expected from the case study climate change altered typhoon at 9 sample points inside Tokyo Bay considering a sea level rise of $0.59 \mathrm{~m}$. The graph also shows the level of the existing sea defences in each of these points by a dotted line, and how at several points the current level of sea defences could be breached.

It is also worth considering how close the defences are to failure, as this can give a feeling of the risks involved. Figure 9 shows the two different cases considered, with case A being the probability of the storm surge will reach a level of at least $50 \mathrm{~cm}$ below the top of the defences, and case B the probability of it overflowing the protection structures. Table 4 computes the probability of each case being reached for each location, for each of the four sea level rise scenarios considered in the present research. This table shows that even with a sea level rise of $0.59 \mathrm{~m}$ there is a strong possibility that storm surge would overflow sea defences at Yokosuka, Yokohama, Kawasaki and Futtsu. If more extreme sea level rise scenarios are used then there is a virtual certainly that a storm surge event would lead to the overflowing of defences throughout Tokyo Bay.
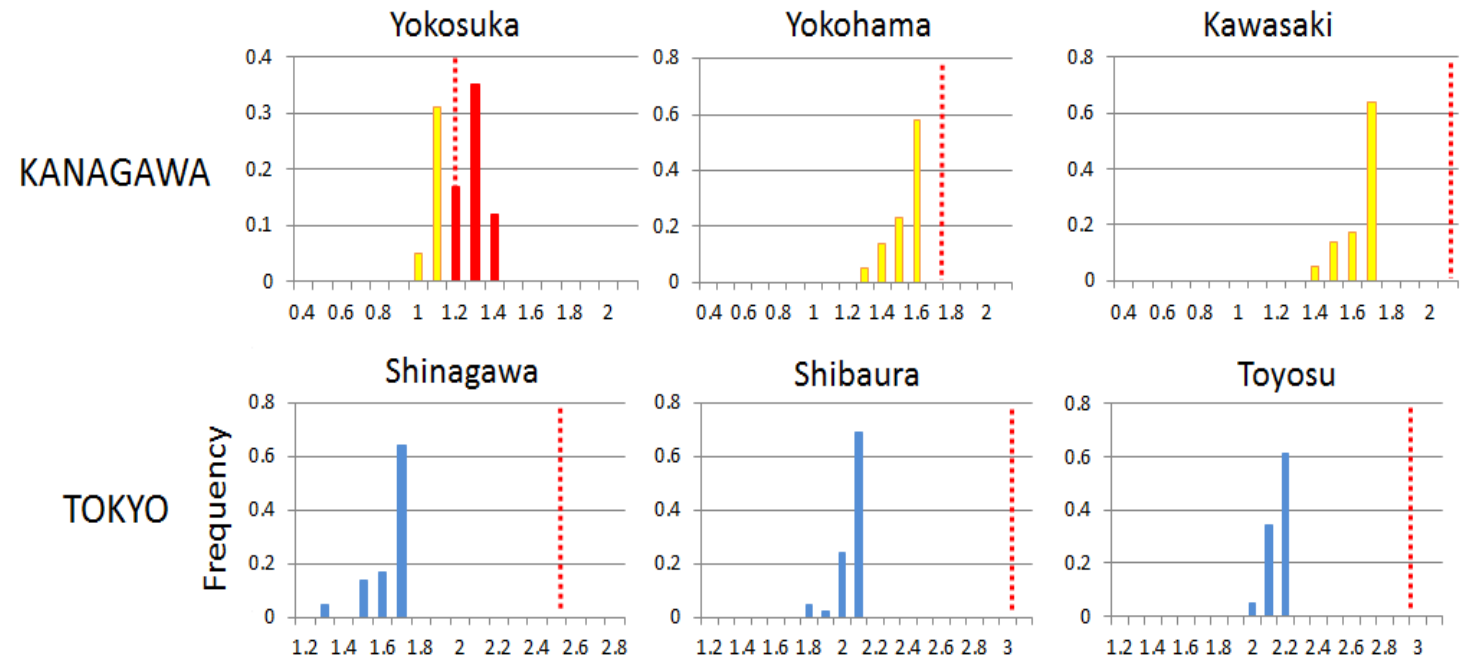

CHIBA
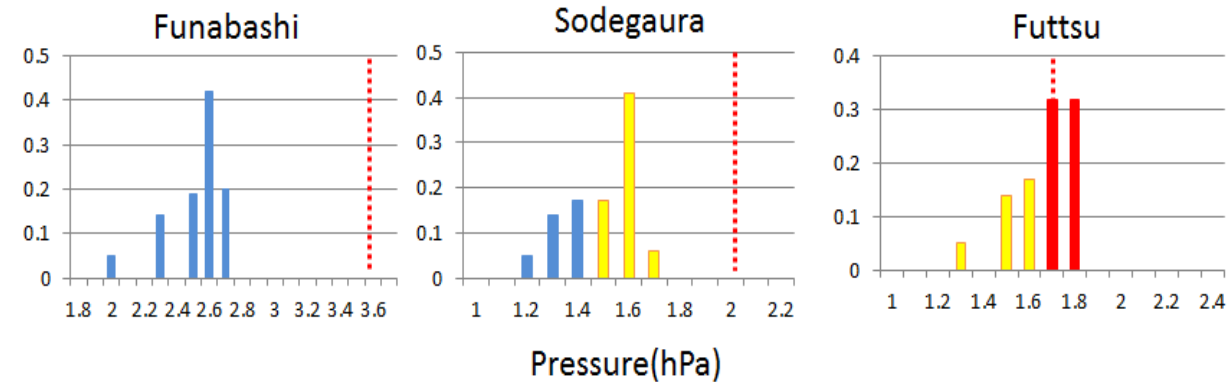

Figure 8. Storm surge at 9 points along Tokyo Bay with a sea level rise of $0.59 \mathrm{~m}$ 


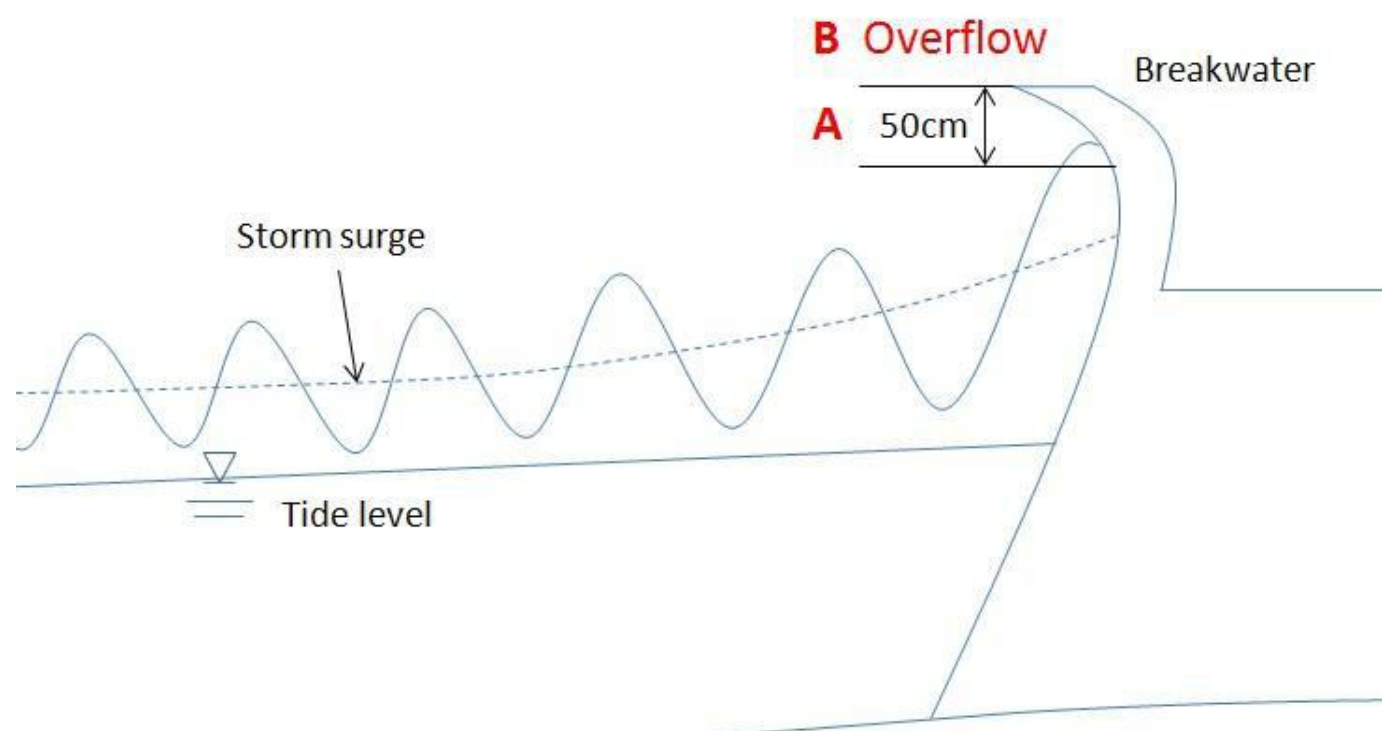

Bottom of the sea

Figure 9. Definition of storm defence cases A and B

\begin{tabular}{|c|c|c|c|c|c|c|c|c|}
\hline \multirow{2}{*}{$\begin{array}{c}\text { Sea level rise } \\
\text { Level of } \\
\text { Storm Surge } \\
\text { Height }\end{array}$} & \multicolumn{2}{|c|}{$0 \mathrm{~cm}$} & \multicolumn{2}{|c|}{$28 \mathrm{~cm}$} & \multicolumn{2}{|c|}{$59 \mathrm{~cm}$} & \multicolumn{2}{|c|}{$190 \mathrm{~cm}$} \\
\hline & A & B & A & B & A & B & A & B \\
\hline Yokosuka & 12 & 0 & 95 & 0 & 100 & 64 & 100 & 100 \\
\hline Yokohama & 0 & 0 & 58 & 0 & 100 & 0 & 100 & 100 \\
\hline Kawasaki & 0 & 0 & 64 & 0 & 100 & 0 & 100 & 100 \\
\hline Samezu & 0 & 0 & 0 & 0 & 0 & 0 & 100 & 100 \\
\hline Shibaura & 0 & 0 & 0 & 0 & 0 & 0 & 100 & 100 \\
\hline Toyosu & 0 & 0 & 0 & 0 & 0 & 0 & 100 & 100 \\
\hline Funabashi & 0 & 0 & 0 & 0 & 0 & 0 & 100 & 81 \\
\hline Sodegaura & 0 & 0 & 0 & 0 & 64 & 0 & 100 & 100 \\
\hline Futtsu & 0 & 00 & 81 & 0 & 100 & 64 & 100 & 100 \\
\hline
\end{tabular}

\section{Population density and elevation map}

Fig.10-12 shows the population density of several areas along Tokyo Bay in Tokyo, Kanagawa and Chiba prefectures, respectively. These figures also show two contour lines, representing the inundation areas that could be affected if the water level reaches the levels indicated (which would result in an overflowing of the coastal dykes). The values indicated are the mean expected storm surge heights which would result as a consequence of the passage of the future typhoon, coupled with a sea level rise of $0.59 \mathrm{~m}$ (Blue line) or $1.90 \mathrm{~m}$ (Light blue line). From these figures it is clear that Tokyo has an expanse of low-level ground which has a very high concentration of population compared to other prefectures. The total population of Tokyo is around 13 million inhabitants (Tokyo Metropolitan Government, 2012), making it the city with the greatest GDP in the world, exceeding even New York City, with a gross output of 1479 billion dollars (PricewaterhouseCoopers, 2009). The Kanto area, however, includes what is called the "greater Tokyo area", including cities such as Yokohama and Kawasaki, and which is estimated to have a population of more than 35 million people, the largest megalopolis in the planet (Japan Statistics Bureau, 2010). This indicated how the possibility that a typhoon causes damage to Tokyo would be important not only for Japan but for the economy of the entire planet, as Tokyo is a financial, commercial, industrial and transport hub.

It is important to note that these figures are not based on inundation simulations, but merely on elevation maps of the city, and thus show the areas potentially at risk rather than those that would necessarily be inundated due to one single event. 


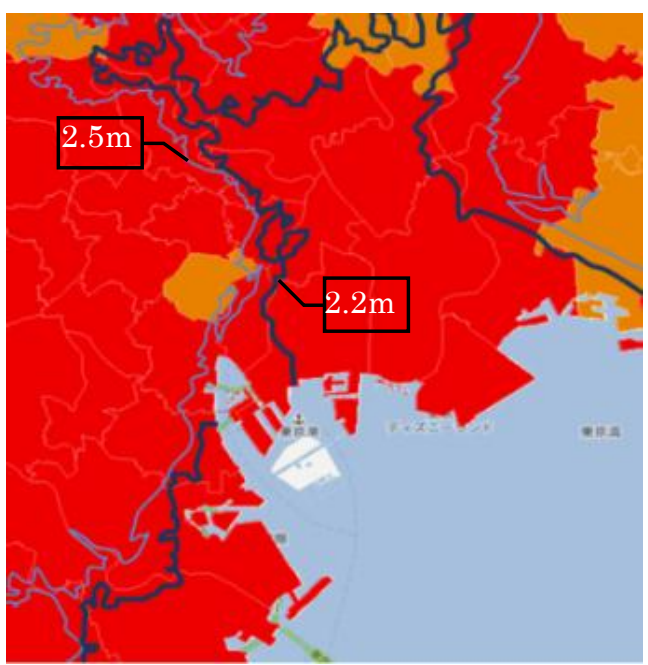

Figure 10. The elevation of storm surge height with a sea level rise of $0.59 \mathrm{~m}$ and $1.90 \mathrm{~m}$ around Tokyo (value in brackets indicates the level of the combined sea level rise and storm surge)

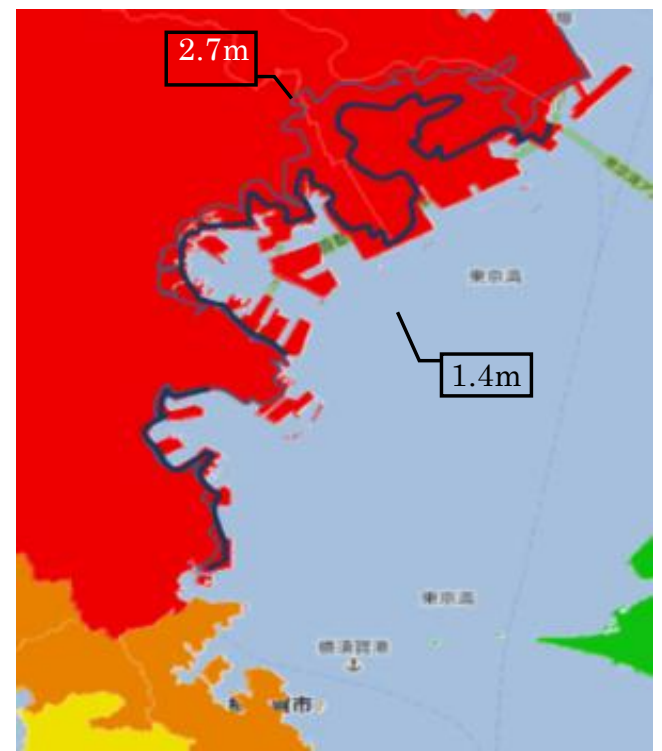

Figure 11. Elevation of storm surge with a sea level rise of $0.59 \mathrm{~m}$ and $1.9 \mathrm{~m}$ around Kanagawa (value in brackets indicates the level of the combined sea level rise and storm surge) 


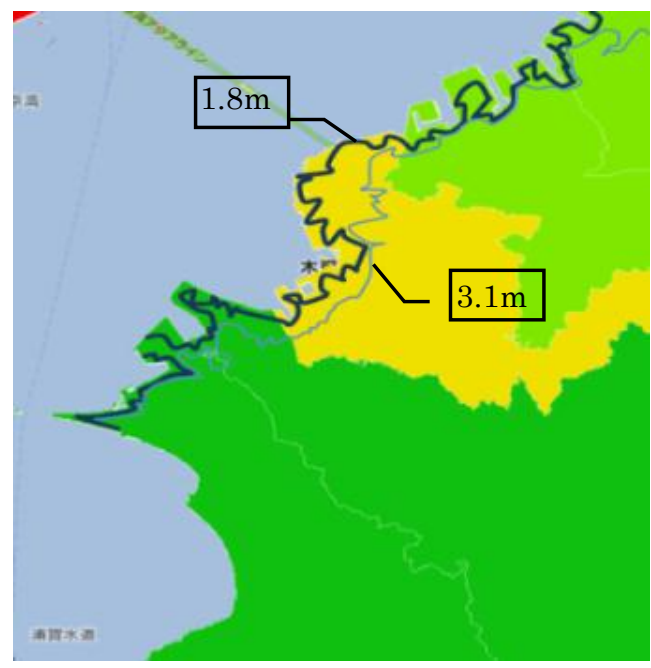

Figure 12. Elevation of storm surge with a sea level rise of $0.59 \mathrm{~m}$ and1.9m around Chiba (value in brackets indicates the level of the combined sea level rise and storm surge)

\section{DISCUSSION}

It is important to remember that not only Tokyo is affected by storm surges. For the case of the 1959 Isewan typhoon in Japan a $3.5 \mathrm{~m}$ storm surge was generated at Nagoya, the principal city for the third biggest economic area in Japan (Kawai et al, 2008). The storm surge breached the weak coastal dykes that existed in the area at the time, flooding the low-lying areas and destroying many timber buildings around Nagoya port (Kawai et al, 2008). After this event the Japanese government started to re-evaluate the storm surge risk amongst many of the vulnerable areas, using the Isewan typhoon as a guide, and throughout the following decades major investments were made in improving coastal defences along major population centres. However, according to Kawai et al. (2008), climate change and its effects in typhoons might result in the lowering of the reliability of the coastal defences (i.e. if the defences are not strengthened various areas in Japan can be expected to be flooded by storm surges more frequently). In this respect, a number of authors have suggested how an increase in typhoon strength can have a number of negative consequences for Japanese port operations (Esteban et al., 2009), coastal defences (Takagi et al. 2011) and the economy in general (Esteban and LongarteGalnares, 2010)

The Taisho $6^{\text {th }}$ typhoon (1917) can be considered to be a typhoon with a $1 / 100$ year return period, as it was the worst typhoon to affect Tokyo Bay in the $20^{\text {th }}$ century. However, a future increase in typhoon intensity as a consequence of climate change will mean that a 1/100 year return period typhoon in the year 2100 will be stronger than now. The methodology described in the present paper allows for the determination of what is a $1 / 100$ year event in the future, by using the probability distribution functions outlined in Yasuda et al. (2010). However, considerable uncertainties exist regarding the likely increase in future typhoon intensity, and it must be understood that the results given in this paper rely on the work of other authors to determine what future increases in intensity will be like.

It is important to also understand the limitations of the model used, which greatly simplifies the calculation of storm surge. The wind field, course of the typhoon and other parameters are idealised in order to save computational time. Such methods have been used in the coastal engineering field for a number of years, though much more advances methods have been recently developed to improve the estimation of storm surge (such as that by Ohira et al. 2012). However, such advanced models require long computational times using super-computers, which make them unviable for the probabilistic approach used in the present paper.

Although the increase in typhoon intensity can contribute to an increase in the flooding risk of coastal areas, for the higher sea level rise scenarios this effect is comparatively less important than the 
increase in mean sea level. Thus, the more onerous sea level rise scenarios would result in a practical certainty of Tokyo Bay being flooded not only by a $1 / 100$ year events but by much more frequent events. Hence, it is very important not only to study the effects that climate change will have on typhoons, but understand better what is the likely pace of sea level rise in the $21^{\text {st }}$ century in order to better design coastal defences.

The flooding of Tokyo Bay could have important consequences for the Japanese economy, as much of the Japanese GDP is concentrated in the Kanto area. Thus, it is important that careful consideration is given to the design of coastal defences around this area of the country. Flooding of these regions could deal a significant and disproportionate blow to the Japanese economy, due to the psychological, cultural and economic impact that such an event would have. The areas that would be flooded also have many subway station and other underground complexes (shopping areas, etc), and thus their flooding would be even more costly and difficult to recover from than the flooding of another area.

\section{CONCLUSION}

The combined effect of an increase in typhoon intensity and sea level rise could pose significant challenges to coastal defences in the Tokyo area. Current Japanese construction policy specifies that coastal defences in the Tokyo Bay area should be constructed to a level of $+4 \mathrm{~m}$ above Tokyo mean water level $(+4 \mathrm{~m}$ T.P., representing $3 \mathrm{~m}$ against storm surge and $1 \mathrm{~m}$ against high tides), though many old structures have been designed to a lower level.

In the present work the authors developed a methodology to determine the change in tropical cyclone intensity around Tokyo Bay, based on the results of Yasuda et al. (2010). The methodology also takes into account a variety of sea level rise scenarios, which have an important effect on the final outcome of the simulations.

To showcase the methodology, the equivalent of Taisho (1917) typhoon was simulated as it moved through the Kanto area. By changing the radius of maximum wind speed of typhoons 10 simulation cases were carried out, giving the probability distribution of storm surge occurrence in the year 2100 . Though the calculated storm surges at Shibaura and Funabashi are high, the risk of overflow is much higher at Yokosuka, Yokohama, Kawasaki, and Futtsu. When the population density and elevation map at Tokyo Bay are considered it can be said that the damage will be more severe at Tokyo city than in other areas, given that a large part of the city is low-lying and that it concentrates a significant proportion of the population and economic activity of the region.

The present results thus showcase how the level of defences could be inadequate by the end of the 21 st century, and that consideration should be given to alternative defensive measures or an increase in the required protection level.

If more onerous sea level rise scenarios are considered, such as those in the IPCC or those by Vermeer and Rahmstorf (2009), this would then require even higher sea defences to be built. In this case the likely increase in storm surge would be small compared to the effect of sea level rise, and would warrant even more dramatic adaptation measures to be taken, which could even include a (very costly and probably environmentally controversial) storm surge barrier across the entrance of Tokyo Bay. This would behave in a similar way to something like the Thames Barrier, but on a far more massive scale. 


\section{REFERENCES}

Allison, I., Bindoff, N.L,. et al. 2009."Copenhagen Diagnosis". The Copenhagen Diagnosis, 2009: Updating the World the Latest Climate Science. http://www.copenhagendiagnosis.org/read/default.html, retrieved $26^{\text {th }}$ January 2010.

Esteban, M., Webersik, C., Shibayama, T. 2009. Methodology for the Estimation of the Increase in Time Loss Due to Future Increase in Tropical Cyclone Intensity in Japan, Journal of Climatic Change, Volume 102, Numbers 3-4,pp. 555-578

Esteban M. and Longarte-Galnares, G. 2010. Evaluation of the Productivity Decrease Risk due to a Future Increase in Tropical Cyclone Intensity in Japan, Journal of Risk Analysis, pages 1789-1802

Japan Statistics Bureau. 2010. http://www.e-stat.go.jp/SG1/estat/XlsdlE.do?sinfid=000008640423 Accessed 15 Sept 2012

Kawai, H., Hashimoto, N., Matsuura, K. 2008. Estimation of Extreme Storm Water Level in Japanese Bays by using Stochastic Typhoon Model and Tide Observation Data. Proc. 18 ${ }^{\text {th }}$ (2008) International Offshore and Polar Engineering Conference, Vancouver, BC, Canada, July 6-11, 2008.

Knutson, T., McBride, J., Chan, J., Emanuel, K., Holland, G., Landsea, C., Held, I., Kossin, J., Srivastava, A., \& Sugi, M. 2010. Tropical cyclones and climate change. Nature Geoscience, 3 (3), 157-163 DOI: 10.1038/ngeo779

Masamori, M. 2003.Study of storm surge. Seizando-shoten Publishing. pp30-33.

Mousavi, M. E., Irish, J. L., Frey, A. E., Olivera, F., and Edge, B. L. (2011). Global warming and hurricanes: the potential impact of hurricane intensification and sea level on coastal flooding. Climatic Change 104: 575-597.

Myers, V.A. 1954. Characteristics of United States Hurricanes Pertinent to Levee Design for Lake Okeechobee, Florida. Hydro-Meteorological Report of U.S Weather Bureau, 32, pp.1-106.

Ohira, K., Shibayama, T., Esteban, M., Mikami, T., Takabatake, T. and Kokado, M. 2012 Comprehensive Numerical Simulation of Waves Caused by Typhoon Using a Meteorology-WaveStorm Surge-Tide Coupled Model. Proc. of 32nd Int. Conf. on Coastal Engineering (ICCE 2012), Santander, Spain.

Pielke Jr., R. A. 2007 Future Economic Damage from Tropical Cyclones. Sensitivities to Societal and Climate Changes, Philosophical. Transactions of the Royal Society, DOI:10.1098/rsta.2007.2086.

Shibayama, T. Okayasu, A. and Mchio, T. .1990.A numerical calculation of storm surge in Tokyo Bay by using Two-level model. Annual Journal of Civil Engineering in the Ocean, JSCE.6.pp77-82

Takagi, H., Kashihara, H., Esteban, M. and Shibayama, T. 2011. Assessment of Future Stability of Breakwaters under Climate Change, Coastal Engineering Journal, Vol. 53, No. 1

Tokyo Metropolitan Government(2012) http://www.metro.tokyo.jp/ENGLISH/PROFILE/overview03.htm. Accessed 15 Sept 2012

Pricewaterhouse Coopers (2009) http://www.pwc.com/ Accessed 15 Sept 2012

Vermeer M and Rahmstorf S PNAS 2009;106:21527-21532

Yasuda, T. Hayashi, Mori, N. and Mase, H. 2010. A Stochastic Typhoon Model Applicable to Storm Surge and Wave Simulations for Climate Change, Proceedings of JSCE, Vol. 66, No. 1, 12411245.

Yasuda, T. Mase, H. and Mori. N, 2010. Projection of future typhoons landing on Japan based on a stochastic typhoon model utilizing AGCM projections, Hydrological Research Letters, 4. 65-69. 